\title{
cJUN N-terminal kinase (JNK) activation mediates islet amyloid-induced beta cell apoptosis in cultured human islet amyloid polypeptide transgenic mouse islets
}

\author{
S. L. Subramanian • R. L. Hull • S. Zraika • \\ K. Aston-Mourney • J. Udayasankar • S. E. Kahn
}

Received: 21 March 2011 / Accepted: 12 September 2011 / Published online: 26 October 2011

(C) Springer-Verlag (outside the USA) 2011

\begin{abstract}
Aims/hypothesis Aggregation of human islet amyloid polypeptide (hIAPP) as islet amyloid is associated with increased beta cell apoptosis and reduced beta cell mass in type 2 diabetes. Islet amyloid formation induces oxidative stress, which contributes to beta cell apoptosis. The cJUN N-terminal kinase (JNK) pathway is a critical mediator of beta cell apoptosis in response to stress stimuli including oxidative stress and exogenous application of hIAPP. We determined whether amyloid formation by endogenous hIAPP mediates beta cell apoptosis through JNK activation and downstream signalling pathways.

Methods $\mathrm{h} I A P P$ transgenic and non-transgenic mouse islets were cultured for up to $144 \mathrm{~h}$ in $16.7 \mathrm{mmol} / 1$ glucose to induce islet amyloid in the presence or absence of the amyloid inhibitor Congo Red or a cell-permeable JNK inhibitor. Amyloid, beta cell apoptosis, JNK signalling and activation of downstream targets in the intrinsic and extrinsic apoptotic pathways were measured.

Results JNK activation occurred with islet amyloid formation in $\mathrm{h} I A P P$ transgenic islets after 48 and $144 \mathrm{~h}$ in culture. Neither high glucose nor the $\mathrm{h} I A P P$ transgene alone was sufficient to activate JNK independent of islet amyloid. Inhibition of islet amyloid formation with Congo Red reduced beta cell apoptosis and partially decreased JNK activation. JNK inhibitor treatment reduced beta cell apoptosis without affecting islet amyloid. Islet amyloid increased mRNA levels of markers of the extrinsic (Fas,
\end{abstract}

S. L. Subramanian • R. L. Hull • S. Zraika • K. Aston-Mourney • J. Udayasankar $\cdot$ S. E. Kahn $(\bowtie)$

Division of Metabolism, Endocrinology, and Nutrition, Department of Medicine, VA Puget Sound Health Care System and University of Washington,

1660 South Columbian Way,

Seattle, WA 98108, USA

e-mail:skahn@u.washington.edu
$F a d d$ ) and intrinsic (Bim [also known as Bcl2l11]) apoptotic pathways, caspase 3 and the anti-apoptotic molecule $B c l x l$ (also known as Bcl2l1) in a JNK-dependent manner.

Conclusions/interpretation Islet amyloid formation induces JNK activation, which upregulates predominantly proapoptotic signals in both extrinsic and intrinsic pathways, resulting in beta cell apoptosis.

Keywords Beta cell apoptosis · hIAPP - Islet amyloid ·NK activation

$\begin{array}{ll}\text { Abbreviations } \\ \text { BAD } & \text { BCL2-associated agonist of cell death } \\ \text { BCL2 } & \text { B-cell leukaemia/lymphoma 2 } \\ \text { BCLXL } & \text { BCL2-like protein 1 } \\ \text { BH3 } & \text { BCL2 homology domain 3 } \\ \text { BIM } & \text { BCL2-interacting mediator of cell death } \\ \text { CASP3 } & \text { Caspase 3 } \\ \text { ER } & \text { Endoplasmic reticulum } \\ \text { FADD } & \text { FAS-associated death domain } \\ \text { hIAPP } & \text { Human islet amyloid polypeptide } \\ \text { IAPP } & \text { Islet amyloid polypeptide } \\ \text { JNK } & \text { cJUN N-terminal kinase } \\ \text { p-cJUN } & \text { Phosphorylated cJUN } \\ \text { p-JNK } & \text { Phosphorylated JNK }\end{array}$

\section{Introduction}

Islet amyloid formation is a pathological hallmark of type 2 diabetes occurring in the majority of patients [1], and is associated with decreased beta cell mass and function $[2,3]$. The unique polypeptide constituent of these amyloid deposits is islet amyloid polypeptide (IAPP), which is a normally soluble secretory product of the beta 
cell released with insulin [4-6]. Human IAPP (hIAPP) is amyloidogenic in contrast to rodent IAPP, due to differences at several critical amino acid residues [7].

The process of amyloid formation involves aggregation of IAPP monomers to form oligomers and then fibrils, ultimately leading to insoluble amyloid deposits [2]. Several studies have shown that early hIAPP aggregates are cytotoxic, resulting in beta cell apoptosis in cultured cells and islets [813]. Oxidative stress has been shown to be a mediator of hIAPP/amyloid-induced beta cell apoptosis. In human autopsy samples of patients with type 2 diabetes, islet amyloid was associated with oxidative stress markers [14]. Furthermore, in an in vitro culture model of islet amyloid using isolated islets from $\mathrm{h} I A P P$ transgenic mice, we showed that amyloid formation induces oxidative stress, which timedependently potentiates amyloid formation and contributes to increased beta cell apoptosis [15]. The relationship between islet amyloid and endoplasmic reticulum (ER) stress is less clear. Human autopsy samples have shown that type 2 diabetes is associated with ER stress [16], but that islet amyloid is not [17]. Amyloid formation was not associated with ER stress in our in vitro model [17]. However, studies in mouse and rat models of amyloid formation with transgenic overproduction of hIAPP have shown that under conditions of increased hIAPP levels, ER stress is a potential mediator of hIAPP-induced beta cell apoptosis $[18,19]$.

The signalling pathways that mediate beta cell apoptosis downstream of islet amyloid formation from endogenously produced hIAPP have yet to be fully characterised. The cJUN N-terminal kinase (JNK) pathway is an important central proapoptotic pathway in the beta cell, which is activated in response to several stress stimuli including high glucose [20], NEFA [21], pro-inflammatory cytokines [22, 23], and both oxidative and ER stress [21, 24]. JNK also mediates beta cell apoptosis in cultured cell lines or isolated islets exposed to acute, supraphysiological (micromolar) concentrations of synthetic hIAPP [25-27]. Furthermore, the FAS-associated death receptor pathway and caspase 3 (CASP3) have been implicated downstream of JNK signalling in exogenous hIAPP-mediated cytotoxicity [28]. However, whether the JNK pathway also mediates beta cell apoptosis due to amyloid formed from endogenous hIAPP produced at physiological concentrations is the focus of this study.

The intricacies of the apoptotic pathways and specifically those downstream of JNK, although well studied in other cell types, have not been well characterised in the beta cell [29]. In neurons, a cell with similarities to the beta cell [30], JNK signalling plays a critical role in the extrinsic and intrinsic pathways of apoptosis by regulating the transcription of proapoptotic molecules and post-translational modification of both pro- and anti-apoptotic molecules. Thus, in this study, we sought to identify JNK-dependent candidate signals in the extrinsic and intrinsic pathways of apoptosis that are activated by endogenously produced hIAPP during amyloid formation and may contribute to beta cell apoptosis.

\section{Methods}

Transgenic mice Hemizygous $\mathrm{h} I A P P$ transgenic mice [31] on an $\mathrm{F} 1 \mathrm{C} 57 \mathrm{BL} / 6 \times \mathrm{DBA} / 2 \mathrm{~J}$ background were used in this study with non-transgenic littermates as controls. Polymerase chain reaction was used to determine transgenic status as previously described [32]. The study was approved by the Institutional Animal Care and Use Committee at the VA Puget Sound Health Care System.

Islet isolation and culture Islets were isolated from 10week-old male and female mice as previously described [33]. After overnight recovery, islets were cultured for up to $144 \mathrm{~h}$ in medium containing 11.1 or $16.7 \mathrm{mmol} / \mathrm{l}$ glucose in the presence or absence of the amyloid inhibitor Congo Red (200 $\mu \mathrm{mol} / \mathrm{l})$ [15], cell-permeable JNK inhibitor peptide (JNK inhibitor 1, L-form; $10 \mu \mathrm{mol} / 1$; EMD Chemicals, Gibbstown, NJ, USA) [20, 26, 34] or a negative control peptide (JNK inhibitor 1-negative control, L-form; $10 \mu \mathrm{mol} / \mathrm{l}$; EMD Chemicals). JNK inhibitor 1 contains the minimal 20-amino acid inhibitory domain of islet brain-1 protein linked to a 10amino acid HIV-TAT sequence that rapidly translocates into the cell and has been shown to reduce JNK-mediated activation of cJUN [34]. The $10 \mu \mathrm{mol} / 1$ dose of JNK inhibitor was chosen based on efficacy to reduce phosphorylated (p)cJUN levels with tested doses ranging from 1 to $10 \mu \mathrm{mol} / \mathrm{l}$.

Histological assessment of islet amyloid and beta cell apoptosis Islets were fixed in $4 \%$ (wt/vol.) phosphatebuffered paraformaldehyde and embedded in paraffin. Ten micrometer sections were stained with thioflavin S, insulin antibody and Hoechst 33258 to visualise amyloid deposits, beta cells and nuclei, respectively [33]. Beta cell apoptosis was quantified by staining islets with propidium iodide and anti-insulin antibody [15]. Histological assessment of both islet amyloid and beta cell apoptosis was carried out by a single investigator who was blinded to both genotype and experimental treatment for each sample. An average of 16 islets per experimental condition was analysed. Amyloid severity (per cent of islet area occupied by amyloid) was computed using Image Pro Plus (Media Cybernetics, Bethesda, MD, USA) by determining the thioflavin S and insulin-positive areas within each islet cross-section [33]. The proportion of apoptotic beta cells was calculated by manually counting the number of condensed and fragmented nuclei in insulin-positive cells [15].

Protein extraction and assessment of JNK activation Islets (200 per condition) were lysed (Bio-Plex Cell Lysis Kit, 
Bio-Rad Laboratories, Hercules, CA, USA) and sonicated. Supernatants were collected and protein concentration was determined using the bicinchoninic acid assay.

p-cJUN and total cJUN were measured in islet lysates $(250 \mu \mathrm{g} / \mathrm{ml})$ using the Bio-Rad phosphoprotein immunoassay kit and Bio-Plex 200 suspension array system (Bio-Rad Laboratories). For western blots, islet protein $(20 \mu \mathrm{g})$ was loaded on a $12 \%$ sodium dodecyl sulphatepolyacrylamide gel transferred to polyvinylidene difluoride membrane and probed with anti-p-JNK, anti-p-cJUN or total cJUN (1:500; Cell Signaling, Danvers, MA, USA), followed by goat anti-rabbit immunoglobulin/ horseradish peroxidase (HRP) (1:50,000; Dako, Carpinteria, CA, USA). Membranes were stripped (Restore PLUS Western Blot Stripping Buffer Kit, Thermo Scientific, Rockford, IL, USA) and reprobed with anti- $\beta$-actin $(1: 2,000$; Sigma, St Louis, MO, USA) as a loading control, followed by goat anti-rabbit immunoglobulin/HRP (1:75,000, Dako). Immunoreactive bands were detected by enhanced chemiluminescence as described by the manufacturer (Thermo Scientific) and quantified using ImageJ software (National Institutes of Health, Bethesda, MD, USA). The densities of p-JNK, p-cJUN and total cJUN were expressed as a ratio of $\beta$-actin.

$R N A$ isolation and real-time quantitative reverse transcription-PCR Total islet RNA was isolated from 25 islets per condition (High Pure RNA Isolation Kit, Roche Applied Science, Indianapolis, IN, USA) and reverse transcribed (High Capacity cDNA Archive Kit, Applied Biosystems, Foster City, CA, USA) [33]. mRNA levels of cJun, the pro-apoptotic genes Fas, Fadd, Bim (also known as Bcl2l11) and Casp3, and the anti-apoptotic genes Bclxl (also known as Bcl2ll) and Bcl2 were measured in triplicate by real-time PCR using TaqMan assays on demand (ABI Prism 7500; Applied Biosystems) [15, 33]. As an endogenous control, 18S ribosomal RNA levels were used. mRNA levels were expressed relative to nontransgenic islets cultured in $16.7 \mathrm{mmol} / \mathrm{l}$ glucose alone using the $\Delta \Delta \mathrm{C}_{\mathrm{t}}$ method.

Statistical analyses Data are expressed as mean \pm SEM. Data were compared by analysis of variance with post hoc analysis or with Mann-Whitney $U$ test if they were not normally distributed. A $p<0.05$ was considered statistically significant.

\section{Results}

Glucose dependence of islet amyloid formation, beta cell apoptosis and JNK activation Culture of $\mathrm{h} I A P P$ transgenic islets in $11.1 \mathrm{mmol} / \mathrm{l}$ glucose for $48 \mathrm{~h}$ was associated with minimal amyloid formation, whereas culture in $16.7 \mathrm{mmol} / 1$ glucose induced islet amyloid formation (Fig. 1a). As expected, non-transgenic islets did not form amyloid.

Islet amyloid formation over $48 \mathrm{~h}$ in $16.7 \mathrm{mmol} / \mathrm{l}$ glucose was associated with increased beta cell apoptosis (Fig. 1b) and JNK activation, the latter shown as increases in both p-JNK (Fig. 1c, d) and p-cJUN levels (Fig. 1e) compared with nontransgenic islets cultured in $16.7 \mathrm{mmol} / \mathrm{l}$ glucose. Both $\mathrm{h} I A P P$ transgenic islets cultured in $11.1 \mathrm{mmol} / \mathrm{l}$ glucose and non-transgenic islets cultured in $16.7 \mathrm{mmol} / \mathrm{l}$ glucose demonstrated similar levels of $\mathrm{p}$-JNK and p-cJUN to nontransgenic islets cultured in $11.1 \mathrm{mmol} / \mathrm{l}$ glucose (Fig. 1c-e).

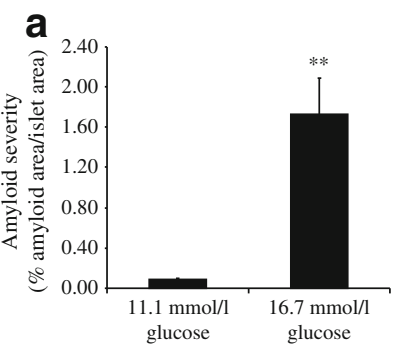

b
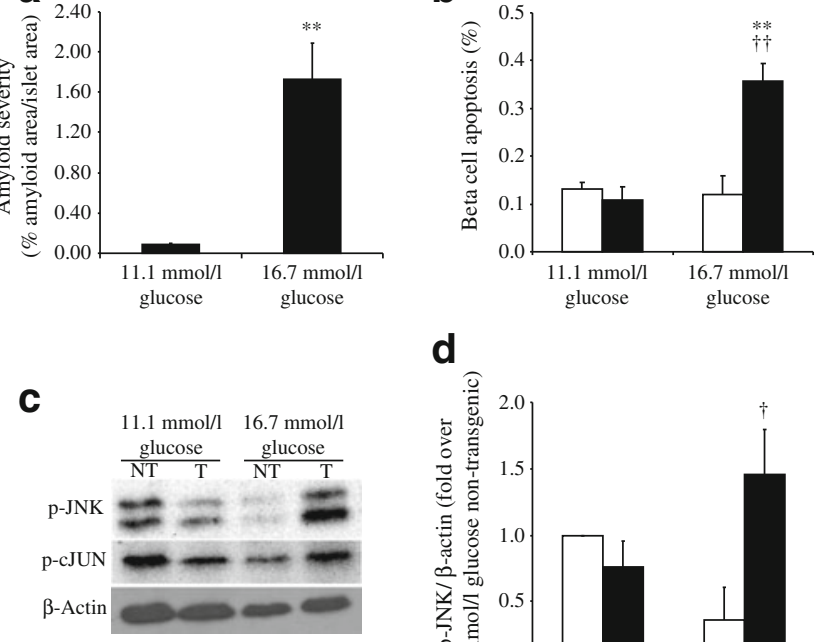

d
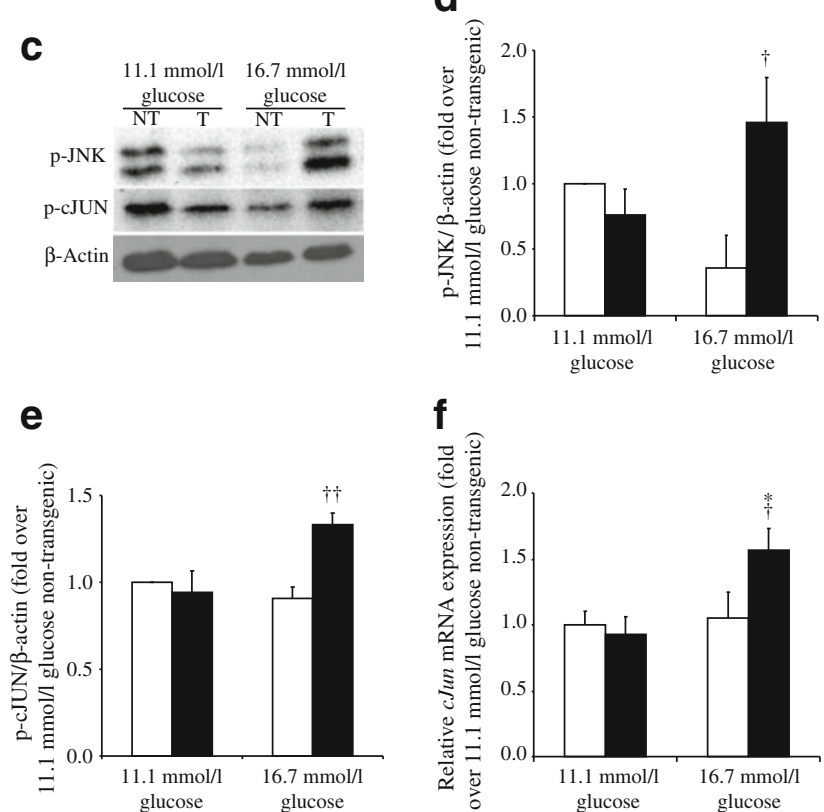

Fig. 1 Islet amyloid severity (per cent islet area occupied by amyloid) (a) and beta cell apoptosis (per cent apoptotic beta cells/total cells) (b) in non-transgenic (NT; white bars) and $\mathrm{h} I A P P$ transgenic (T; black bars) islets cultured in 11.1 and $16.7 \mathrm{mmol} / \mathrm{l}$ glucose for $48 \mathrm{~h}$. Nontransgenic islets did not form amyloid. p-JNK and p-cJUN levels were measured by western blot in non-transgenic and $\mathrm{h} I A P P$ transgenic islets using $\beta$-actin as a loading control and representative western blots are shown in (c). Quantification of $\mathrm{p}-\mathrm{JNK} / \beta$-actin and $\mathrm{p}$-cJUN/ $\beta$-actin are shown in (d) and (e), respectively. cJun mRNA levels are shown in (f). $n=4-6 ;{ }^{*} p<0.05$ and $* * p<0.01$ vs $\mathrm{h} I A P P$ transgenic islets cultured in $11.1 \mathrm{mmol} / 1$ glucose. ${ }^{\dagger} p<0.05$ and ${ }^{\dagger \dagger} p<0.01$ vs nontransgenic islets cultured in $16.7 \mathrm{mmol} / 1$ glucose 
cJun mRNA levels increased by $60 \%$ in $\mathrm{h} I A P P$ transgenic islets cultured in $16.7 \mathrm{mmol} / \mathrm{l}$ glucose compared with those cultured in $11.1 \mathrm{mmol} / 1$ glucose and non-transgenic islets (Fig. 1f).

Time dependence of islet amyloid formation and JNK activation Islet amyloid formation in $\mathrm{h} I A P P$ transgenic islets increased over the $144 \mathrm{~h}$ culture period (Fig. 2a). p-cJUN and total cJUN levels did not change in non-transgenic islets over time (Fig. 2b, c). p-cJUN levels were higher in $\mathrm{h} I A P P$ transgenic islets compared with non-transgenic islets as early as $48 \mathrm{~h}$ and this increase persisted at $144 \mathrm{~h}$ (Fig. 2b). Although total cJUN levels were not significantly increased in $\mathrm{h} I A P P$ transgenic islets following $48 \mathrm{~h}$ of culture, they were significantly increased after $144 \mathrm{~h}$ of culture (Fig. 2c). cJun mRNA levels increased in hIAPP transgenic compared with non-transgenic islets cultured for $144 \mathrm{~h}$ (Fig. 2d).
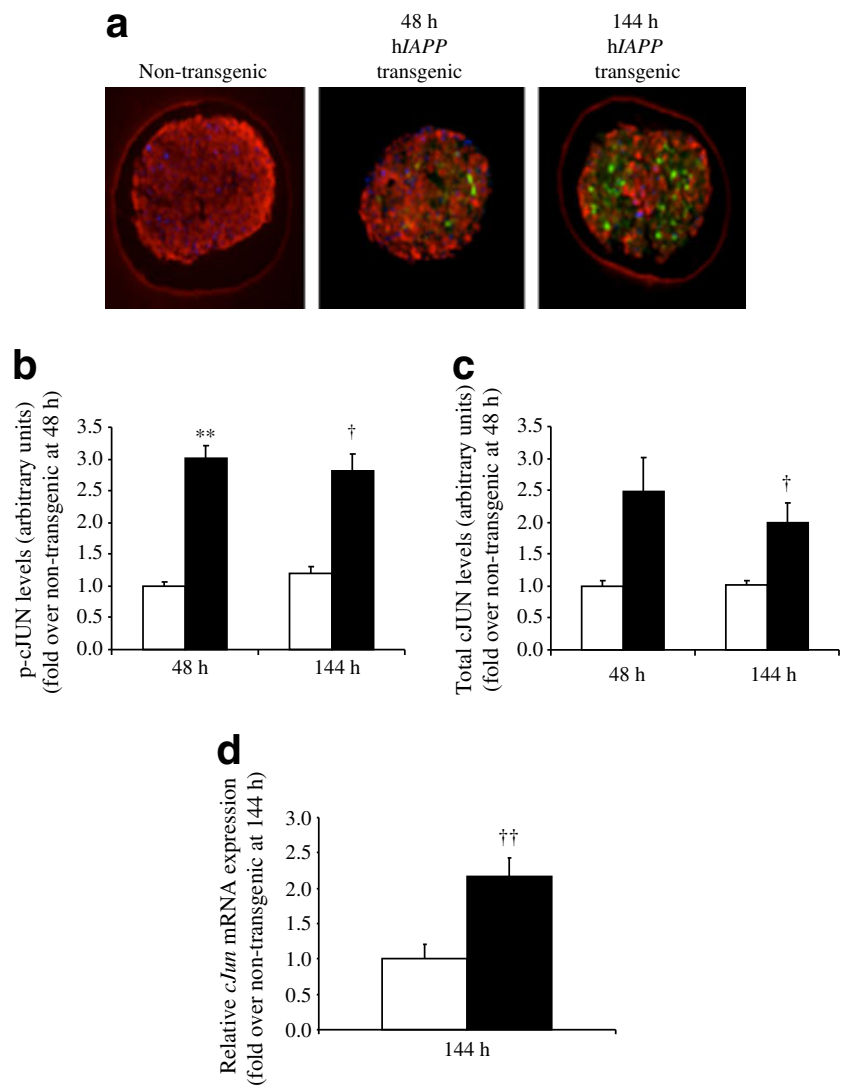

Fig. 2 Representative amyloid (green), insulin (red) and nuclear (blue) staining (a) in non-transgenic and $\mathrm{h} I A P P$ transgenic islets cultured in $16.7 \mathrm{mmol} / \mathrm{l}$ glucose over $144 \mathrm{~h}$. p-cJUN (b) and total cJUN (c) levels at 48 and $144 \mathrm{~h}$ were measured by Bio-Plex immunoassay in both non-transgenic (white bars) and $\mathrm{h} I A P P$ transgenic (black bars) islets. Data are expressed in arbitrary units relative to non-transgenic islets cultured for $48 \mathrm{~h}$. cJun mRNA levels measured in non-transgenic and $\mathrm{h} I A P P$ transgenic islets after $144 \mathrm{~h}$ are shown in (d). $n=4-6 ;{ }^{* *} p \leq$ 0.01 vs non-transgenic islets cultured for $48 \mathrm{~h} .{ }^{\dagger} p<0.05$ and ${ }^{\dagger \dagger} p<0.01$ vs non-transgenic islets cultured for $144 \mathrm{~h}$
Effect of the islet amyloid inhibitor Congo Red on islet amyloid severity, beta cell apoptosis and JNK activation Congo Red treatment inhibited amyloid formation in $\mathrm{h} I A P P$ transgenic islets (Fig. 3a), and this was associated with a reduction in beta cell apoptosis in $\mathrm{h} I A P P$ transgenic islets to levels similar to those in non-transgenic islets (Fig. 3b). Congo Red treatment also partially decreased p-cJUN levels (Fig. 3c), an observation that was confirmed by western blot (data not shown).

Effect of JNK inhibition on p-cJUN levels, islet amyloid severity and beta cell apoptosis JNK inhibition did not change p-cJUN levels in non-transgenic islets (Fig. 4a), whereas in $\mathrm{h} I A P P$ transgenic islets it resulted in a $45 \%$ reduction in p-cJUN levels, making them similar to those in non-transgenic islets (Fig. 4a). Negative control peptide treatment $(10 \mu \mathrm{mol} / \mathrm{l} ; n=3)$ resulted in no differences in $\mathrm{p}$ cJUN levels in either non-transgenic islets $(1.05 \pm 0.22 \mathrm{vs}$ 1.00 ratio of $\mathrm{p}$-cJUN/ $\beta$-actin expressed as fold over nontransgenic islets cultured in $16.7 \mathrm{mmol} / 1$ glucose; $p=0.83$ ) or $\mathrm{h} I A P P$ transgenic islets $(1.75 \pm 0.38$ vs $3.02 \pm 1.43$ ratio of $\mathrm{p}$-cJUN $/ \beta$-actin expressed as fold over non-transgenic islets cultured in $16.7 \mathrm{mmol} / \mathrm{l}$ glucose; $p=0.36$ ).

Co-culture of hIAPP transgenic islets with the JNK inhibitor had no effect to reduce islet amyloid formation (Fig. 4b). Similarly, the negative control peptide had no effect on amyloid formation $(0.90 \pm 0.14 \%$ vs $0.58 \pm 0.05$; $p=$ $0.17)$. JNK inhibition resulted in no significant difference in
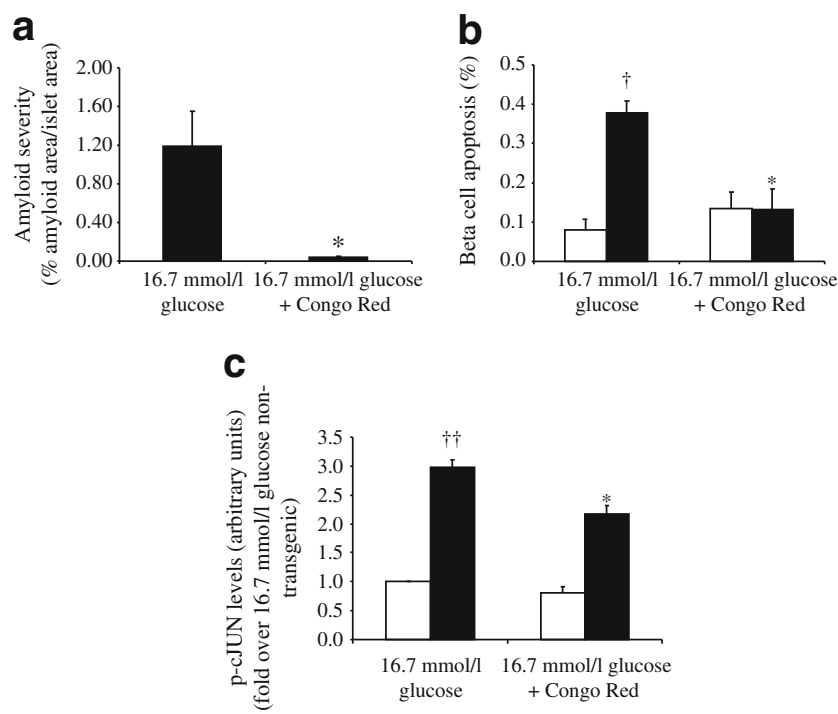

Fig. 3 Islet amyloid severity (a), beta cell apoptosis (b) and p-cJUN levels measured by Bio-Plex immunoassay (c) in non-transgenic (white bars) and hIAPP transgenic (black bars) islets cultured in $16.7 \mathrm{mmol} / \mathrm{l}$ glucose for $48 \mathrm{~h}$ in the absence or presence of Congo Red $(200 \mu \mathrm{mol} / \mathrm{l})$, an amyloid inhibitor. Non-transgenic islets did not form amyloid. $n=4 ;{ }^{*} p<0.05$ vs $\mathrm{h} I A P P$ transgenic islets cultured in $16.7 \mathrm{mmol} / 1$ glucose. ${ }^{\dagger} p<0.01$ vs non-transgenic islets cultured in $16.7 \mathrm{mmol} / 1$ glucose 

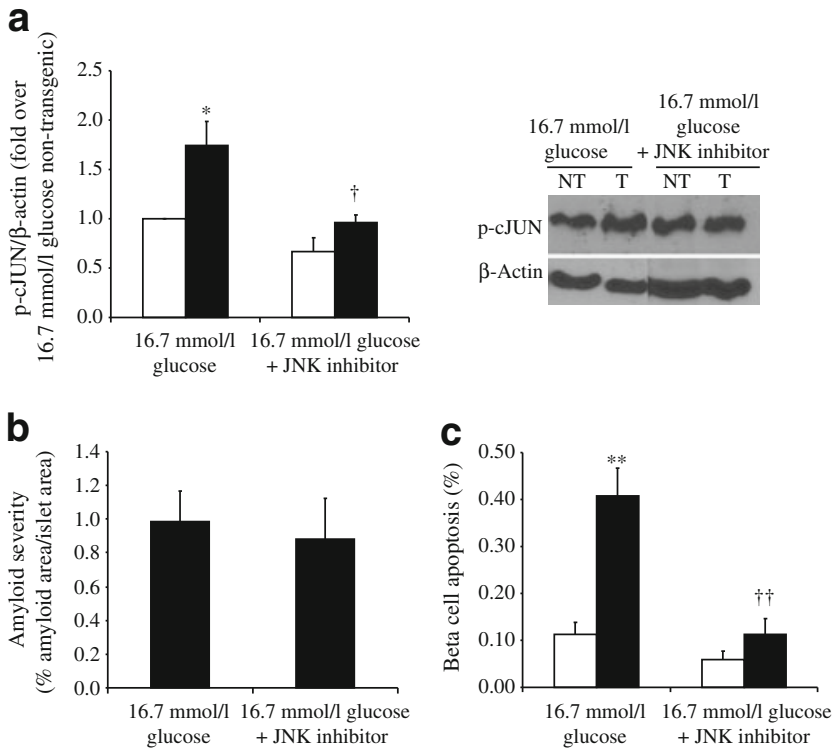

Fig. 4 Effect of JNK inhibitor treatment $(10 \mu \mathrm{mol} / \mathrm{l})$ on p-cJUN levels measured by western blot (a), islet amyloid severity (b) and beta cell apoptosis (c) in non-transgenic (NT, white bars) and hIAPP transgenic (black bars) islets cultured in $16.7 \mathrm{mmol} / 1$ glucose for $48 \mathrm{~h}$. p-cJUN levels were quantified and expressed as a ratio p-cJUN/ $\beta$ actin. Non-transgenic islets did not form islet amyloid. $n=6 ; * p<0.05$ and $* * p<0.01$ vs non-transgenic islets cultured in $16.7 \mathrm{mmol} / 1$ glucose. ${ }^{\dagger} p<0.05$ and ${ }^{\dagger \dagger} p<0.01$ vs $\mathrm{h} / A P P$ transgenic islets cultured in $16.7 \mathrm{mmol} / \mathrm{l}$ glucose

levels of beta cell apoptosis in non-transgenic islets. In contrast, JNK inhibition in $\mathrm{h} I A P P$ transgenic islets resulted in a $72 \%$ reduction in beta cell apoptosis (Fig. 4c). Negative control peptide treatment did not affect beta cell apoptosis as compared with no treatment in either non-transgenic $(0.14 \pm$ $0.02 \%$ vs $0.10 \pm 0.05 \% ; p=0.46)$ or $\mathrm{h} I A P P$ transgenic islets $(0.59 \pm 0.02 \%$ vs $0.48 \pm 0.14 \% ; p=0.28)$.

Islet amyloid-induced, JNK-dependent gene targets in the extrinsic and intrinsic apoptotic pathways mRNA levels of pro- and anti-apoptotic signals were measured in $\mathrm{h} I A P P$ transgenic and non-transgenic islets cultured in $16.7 \mathrm{mmol} / \mathrm{l}$ glucose for $48 \mathrm{~h}$ alone or in the presence of Congo Red or the JNK inhibitor. In the extrinsic pathway, Fas and Fadd were upregulated in $\mathrm{h} I A P P$ transgenic islets (Fig. 5a, b, respectively). In $\mathrm{h} I A P P$ transgenic islets, coculture with Congo Red resulted in a 74\% reduction in Fas mRNA levels with a non-significant decrease in Fadd levels. Co-culture with JNK inhibitor resulted in $74 \%$ and $48 \%$ reductions in Fas and Fadd mRNA levels, respectively. Significant reductions of Fas mRNA levels were observed in non-transgenic islets cultured in the presence of Congo Red and JNK inhibitor.

In the intrinsic pathway, Bim was upregulated in $\mathrm{h} I A P P$ transgenic islets (Fig. 5c). Co-culture with Congo Red or JNK inhibitor resulted in $30 \%$ and $48 \%$ reductions in Bim levels, respectively (Fig. 5c). mRNA levels of Casp3 were upregulated in $\mathrm{h} I A P P$ transgenic islets compared with nontransgenic islets, and were found to be reduced in the presence of Congo Red and JNK inhibitor (Fig. 5d). Levels of the anti-apoptotic factor $B c l x l$ were upregulated in $\mathrm{h} I A P P$ transgenic islets compared with non-transgenic islets, which was abolished by co-culture with Congo Red and JNK inhibitor (Fig. 5e). In contrast, whereas Bcl2 was upregulated in $\mathrm{h} I A P P$ transgenic islets compared with nontransgenic islets, treatment with Congo Red and JNK inhibitor had no effect on Bcl2 mRNA levels (Fig. 5f).

\section{Discussion}

In this study, we sought to determine the mechanism(s) by which islet amyloid formation, under conditions of endogenous hIAPP production, results in beta cell apoptosis. We chose to examine the role of JNK signalling, a pro-apoptotic pathway that mediates beta cell apoptosis in response to several stressors including exogenous hIAPP treatment [25]. We found that JNK signalling is activated during the process of islet amyloid formation, and this occurs in part downstream of amyloid formation. We have also shown that the JNK pathway is a critical mediator of islet amyloid-induced beta cell apoptosis and identified potential downstream mediators in both the extrinsic (Fas and Fadd) and intrinsic (Bim) apoptotic pathways. Last, we observed that the antiapoptotic molecule $B c l x l$ is upregulated in a JNK-dependent manner downstream of islet amyloid formation.

Culture of $\mathrm{h} I A P P$ transgenic islets in high glucose $(16.7 \mathrm{mmol} / \mathrm{l})$ results in light microscopy-visible amyloid deposition and associated beta cell apoptosis [15, 33]. We observed JNK activation, manifest as increased levels of p-JNK and p-cJUN protein and cJun mRNA in $\mathrm{h} I A P P$ transgenic islets only under amyloidogenic $(16.7 \mathrm{mmol} / \mathrm{l}$ glucose) conditions, indicating that the observed $\mathrm{JNK}$ activation was not merely secondary to the expression of the $\mathrm{h} I A P P$ transgene, but rather was dependent on the process of amyloid formation. It has been previously shown that culture of human islets in increased glucose $(33.3 \mathrm{mmol} / \mathrm{l})$ for $18 \mathrm{~h}$ induces JNK activation and beta cell apoptosis [20]. All human islets have the propensity to develop islet amyloid, although this was not examined in the study by Maedler et al. [20], making it difficult to discern whether the observed JNK activation was secondary to high glucose or the presence of amyloid. To control for the potential effect of glucose independent of amyloid, we cultured non-transgenic islets in 11.1 and $16.7 \mathrm{mmol} / \mathrm{l}$ glucose and observed no difference in either p-JNK or p-cJUN protein levels or cJun mRNA levels, demonstrating that increased glucose alone was insufficient for JNK activation. In fact, under increased glucose conditions 

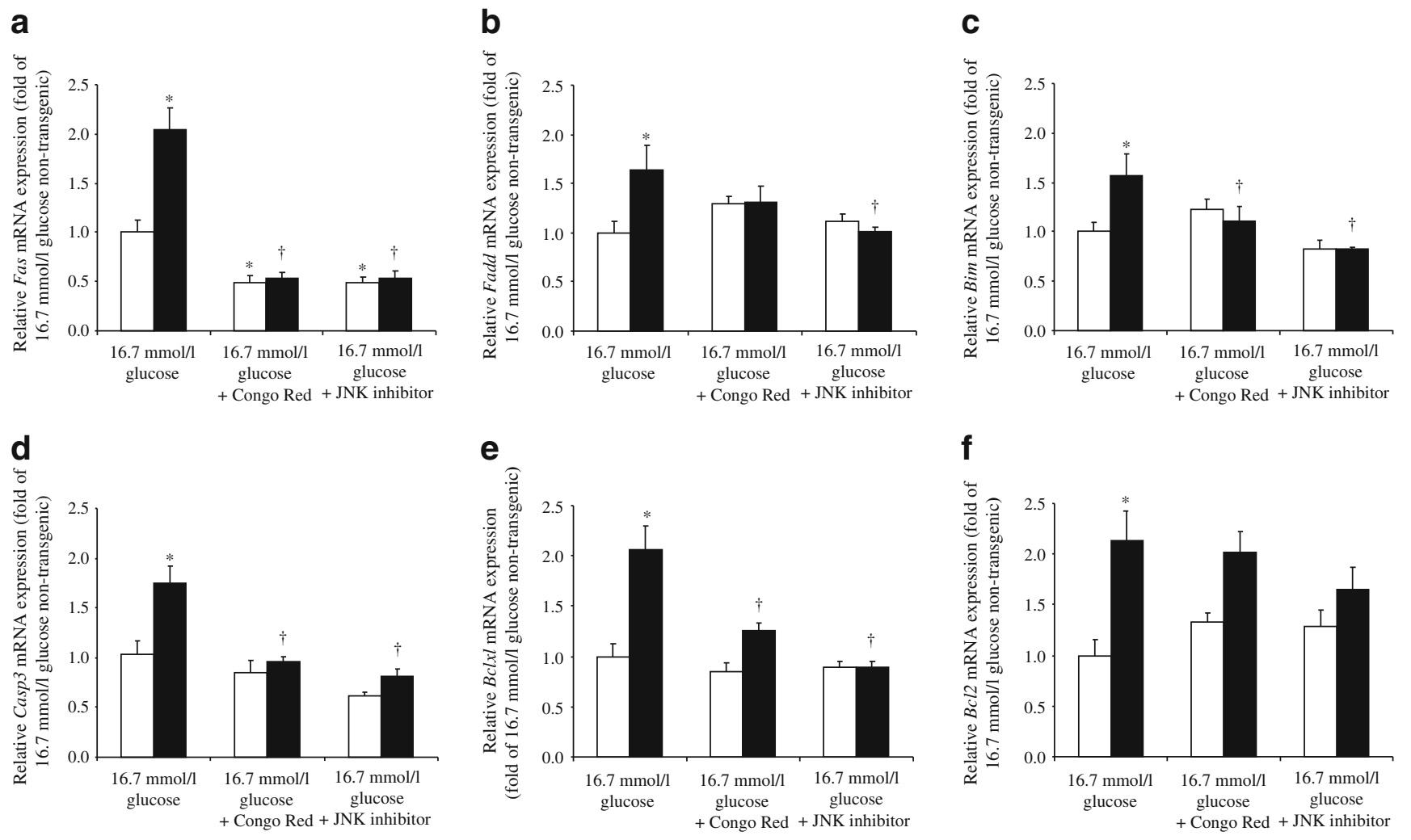

Fig. 5 mRNA levels of pro-apoptotic genes Fas (a), Fadd (b), Bim (c) and Casp3 (d), and anti-apoptotic genes Bclxl (e) and Bcl2 (f) in non-transgenic (white bars) and $\mathrm{h} I A P P$ transgenic (black bars) islets cultured in $16.7 \mathrm{mmol} / \mathrm{l}$ glucose in the absence or presence of Congo
Red $(200 \mu \mathrm{mol} / \mathrm{l})$ or JNK inhibitor $(10 \mu \mathrm{mol} / 1) . n=6 ;{ }^{*} p<0.05$ vs nontransgenic islets cultured in $16.7 \mathrm{mmol} / 1$ glucose. ${ }^{\dagger} p<0.05 \mathrm{vs} \mathrm{h} I A P P$ transgenic islets cultured in $16.7 \mathrm{mmol} / \mathrm{l}$ glucose in non-transgenic islets there was a tendency for a decrease in the activation of JNK that did not coincide with a reduction in phosphorylation of cJUN, an observation that would not be in line with the canonical mechanism of JNK. Thus, we conclude that the observed JNK activation occurs only in the presence of islet amyloid formation.

There are several potential mechanism(s) that underlie islet amyloid-induced JNK activation including oxidative stress, which we have shown to be an important mediator of islet amyloid-induced cytotoxicity [15]. Another possible mechanism is inflammation. Culture of human islets under high glucose, a potentially amyloidogenic condition, stimulates IL-1 $\beta$ production, which mediates beta cell apoptosis [35]. Our recent study demonstrated that fibrillar hIAPP elicits an inflammatory response (including IL-1 $\beta$ production) from bone marrow-derived dendritic cells and showed IL-1 $\beta$ co-localisation with islet amyloid deposits in vivo [36]. It is therefore certainly possible that islet amyloid formation could also induce IL-1 $\beta$ production and JNK activation in beta cells, a scenario requiring further study.

As the process of islet amyloid formation is time dependent [33], we also determined whether JNK activation persists with increasing amyloid formation over time. We demonstrated that JNK is activated in the early stages of amyloid formation (48 h), and remains elevated under more chronic conditions of amyloid deposition (144 h). In contrast, non-transgenic islets demonstrated no increase in JNK activation over time. At $48 \mathrm{~h}$, JNK signalling manifested as increased p-cJUN without a significant increase in total cJUN, although cJun mRNA is increased at this time point. Under the condition of prolonged amyloid formation, increases in p-cJUN, total cJUN and cJun mRNA were observed. This pattern of activation is somewhat consistent with that reported in $16 \mathrm{~h}$ studies in which micromolar concentrations of hIAPP were applied to beta cell lines and increased phosphorylation of cJUN preceded increases in total cJUN [25]. To capture the kinetics of JNK activation in relation to the process of islet amyloid formation in our model, it would have been ideal to examine islets prior to the formation of light microscopyvisible amyloid deposits (prior to $24 \mathrm{~h}$ in culture). However, it is well documented that the islet isolation procedure itself induces stress and JNK activation, precluding this early time point [37]. As isolated islets recover to a low basal rate of JNK signalling following $48 \mathrm{~h}$ in culture [37], we controlled for the stress of isolation by using an overnight recovery period, followed by a minimum of $48 \mathrm{~h}$ in culture prior to making any stress signalling measurements. The 
low, reproducible p-cJUN levels observed in non-transgenic islets suggest that this recovery period is sufficient to control for the confounding effects of the stress of isolation and culture.

To determine whether the JNK pathway is activated upstream or downstream of islet amyloid formation, we interrogated the culture system with the amyloid inhibitor Congo Red. This compound inhibits islet amyloid formation resulting in a rate of beta cell apoptosis in hIAPP transgenic islets similar to that in non-transgenic islets [15]. Treatment with Congo Red resulted in a significant but incomplete reduction in p-cJUN levels. We propose two possible explanations for this observation. First, the JNK signalling pathway is activated in part downstream of islet amyloid but there may be an additional upstream role of JNK signalling. This upstream JNK signalling may (1) play a role in mediating amyloid formation itself or (2) mediate other cytotoxic effects of hIAPP that are potentially amyloid independent. We believe the former is unlikely given that $\mathrm{h} I A P P$ transgenic islets treated with a JNK inhibitor demonstrated no change in amyloid severity. The latter explanation is plausible, although it would be a challenging paradigm to explore in our model in which amyloid is induced as early as $24 \mathrm{~h}$ in culture, and studies prior to this time point are subject to the confounding effects of the stress of isolation.

We have shown that JNK signalling is a critical mediator by which islet amyloid induces beta cell apoptosis. JNK inhibition resulted in reduced beta cell apoptosis in $\mathrm{h} I A P P$ transgenic islets to levels identical to those in non-transgenic islets. Furthermore, JNK signalling under conditions of amyloid formation upregulated mRNA levels of the proapoptotic signalling molecules Fas and Fadd in the extrinsic pathway, Bim in the intrinsic pathway and, as expected, the terminal effector caspase, Casp3, through which both the extrinsic and intrinsic pathways converge to induce apoptosis. The critical role of CASP3 in mediating the toxicity of islet amyloid has been underscored by a recent in vivo study in $\mathrm{h} I A P P$ transgenic mice, which demonstrated that prevention of CASP3 activation protected beta cells from amyloidinduced apoptosis and resulted in preservation of beta cell mass and improved beta cell function [38].

The extrinsic pathway is typically initiated by cell surface death receptors, which includes the FAS ligand receptor, resulting in downstream JNK activation and caspase 8 activation. A recent study has shown that exogenous hIAPP treatment of beta cell lines over an acute culture period of $8 \mathrm{~h}$ results in upregulation of FAS and FAS-associated death domain (FADD), both at the mRNA and protein levels, with associated increases in beta cell apoptosis [28]. Furthermore, this study demonstrated that hIAPP induces FAS through an interaction at the cell surface, which results in JNK activation. JNK signalling is then able to feedback to upregulate levels of FAS, perpetuating a cycle of proapoptotic signalling. These observations are consistent with those in our model of endogenous hIAPP production and islet amyloid formation in which we observe JNK-dependent upregulation of Fas and Fadd.

The intrinsic pathway of apoptosis involves a dynamic interplay between pro-apoptotic B-cell leukaemia/lymphoma 2 (BCL2) homology domain 3 (BH3)-only proteins and antiapoptotic BCL2-like proteins. In response to pro-apoptotic stimuli, BH3-only proteins bind anti-apoptotic BCL2-like proteins, resulting in the release of BCL2-associated agonist of cell death (BAD) and/or BCL2 agonist killer 1 (BAK), which induce changes in mitochondrial membrane permeability and membrane potential causing cytochrome $c$ release and activation of effector caspases to induce apoptosis [39, 40]. We show for the first time that the process of islet amyloid formation and its resultant toxicity activates the proapoptotic BH3-only molecule Bim, in a JNK-dependent manner. The involvement of the intrinsic pathway of apoptosis in the cytotoxicity of islet amyloid is consistent with our previous findings that islet amyloid formation is associated with induction of oxidative stress [15], and oxidative stress is known to activate the intrinsic pathway [41]. In islets, BCL2-interacting mediator of cell death (BIM) has also been shown to be a critical mediator of glucotoxicity and is induced with cytokine treatment, underscoring its importance in mediating apoptosis in response to other types of stress in the islet [40, 42]. Furthermore, exogenous hIAPP treatment of a beta cell line has been shown to (1) upregulate several BH3-only proteins including BCL2-associated protein $\mathrm{X}$ (BAX), BAD, p53-upregulated modulator of apoptosis (PUMA) and truncated BH3-interacting domain death agonist (t-BID), (2) induce cytochrome $c$ release and (3) activate caspase 7 and 9 [43].

The role of the anti-apoptotic proteins and how their dynamic regulation impacts the fate of the beta cell in response to the classic stressors of diabetes is largely unrecognised. Given that we have shown that islet amyloid formation results in beta cell apoptosis, we hypothesised that we may observe downregulation in the anti-apoptotic BCL2-like family of proteins as a potential mechanism of islet amyloid-induced beta cell death. Interestingly, we demonstrated no significant change in the levels of $B c l 2$, and found a JNK-dependent increase in Bclxl in the presence of islet amyloid formation. This is in contrast to studies with exogenous hIAPP treatment, which have found no difference in BCL2-like protein 1 (BCLXL) levels and a small decrease in BCL2 protein levels [43]. The increase in $B c l x l$ in our study may represent a compensatory prosurvival mechanism by which the beta cell is attempting to offset the toxicity of amyloid formation. The induction of anti-apoptotic factors in response to beta cell stress has been observed in islets treated with cytokines [44] and islets 
up to 1 week post transplantation [45]. Although the JNK signalling pathway has classically been thought to be proapoptotic, there is growing evidence that JNK signalling can induce pro-survival pathways in certain cell types, including neurons, T cells and B lymphocytes [46]. The anti-apoptotic response in islets challenged with cytokines is JNK3dependent, which is in contrast to the JNK1 and JNK2 isoforms, which are pro-apoptotic [30]. By using a nonspecific JNK inhibitor, we were unable to differentiate between the contributions of the different JNK isoforms. The significance of JNK-dependent $B c l x l$ upregulation in the presence of islet amyloid as a potential compensatory protective mechanism will require further exploration, and could represent a potential therapeutic target that could be modulated to protect the beta cell from amyloid-induced cytotoxicity.

We used Congo Red, an amyloid inhibitor, which we have shown reproducibly inhibits islet amyloid formation and reduces associated beta cell apoptosis [15]. Interestingly, we observed changes in mRNA levels of some proapoptotic genes in our non-transgenic islets, suggesting that Congo Red may have amyloid-independent effects in islets. Whether this would have long-term deleterious effects is unclear, although a recent report in Caenorhabditis elegans described an extension of lifespan and a slowing of ageing with another amyloid-binding dye, Thioflavin T [47]. Other amyloid inhibitors, including WAS-406 (2-acetamido-1,3, 6-tri- $O$-acetyl-2,4-dideoxy-alpha-D-xylo-hexopyranose), although effective at reducing amyloid deposition, also have amyloid-independent effects and may impact islet cell viability, and as such are limited in their utility [15]. Thus, a consideration in the future development of amyloid inhibitors would be to maximise specificity for amyloid while minimising potential off-target effects.

In summary, we have demonstrated that JNK signalling is a critical mediator of islet amyloid-induced beta cell apoptosis and that pro-apoptotic molecules in the extrinsic and intrinsic pathway are induced by JNK signalling downstream of amyloid formation. Based on these findings, we believe that future studies should evaluate JNK signalling in relation to oxidative stress and the relative contribution and importance of the downstream signalling molecules in the extrinsic and intrinsic pathways in mediating islet amyloid-induced beta cell apoptosis. Interventions targeted to prevent the activation of the JNK pathway and/or downstream mediators induced by islet amyloid may offer therapeutic benefit in minimising toxicity of islet amyloid and the preservation of beta cells in type 2 diabetes.

Acknowledgements We thank B. Barrow, C. Braddock, M. Cone, C. Forsyth, M. Peters, M. Watts and J. Willard for their excellent technical support. This work was supported by the Department of Veterans Affairs and National Institutes of Health grants DK-075998 (S. E. Kahn), DK-074404 (R. L. Hull), DK-080945 (S. Zraika), DK-
007247 and DK-017047. S. Subramanian and K. Aston-Mourney were supported by an American Diabetes Association Mentor-Based Fellowship. K. Aston-Mourney was also supported by a University of Washington McAbee Fellowship. J. Udayasankar was supported by a Juvenile Diabetes Research Foundation Postdoctoral Fellowship.

Contribution statement SLS, RLH, SZ, KA-M, JU and SEK conceived and designed the study, and participated in the analysis and interpretation of the data. SLS drafted the manuscript and all other authors revised it critically for intellectual content. All authors approved the final version of the paper.

Duality of interest The authors declare that there is no duality of interest associated with this manuscript.

\section{References}

1. Westermark P, Wilander E (1978) The influence of amyloid deposits on the islet volume in maturity onset diabetes mellitus. Diabetologia 15:417-421

2. Hull RL, Westermark GT, Westermark P, Kahn SE (2004) Islet amyloid: a critical entity in the pathogenesis of type 2 diabetes. J Clin Endocrinol Metab 89:3629-3643

3. Jurgens CA, Toukatly MN, Fligner CL et al (2011) B-cell loss and B-cell apoptosis in human type 2 diabetes are related to islet amyloid deposition. Am J Pathol 178:2632-2640

4. Westermark P, Wernstedt C, Wilander E, Hayden DW, O'Brien TD, Johnson KH (1987) Amyloid fibrils in human insulinoma and islets of Langerhans of the diabetic cat are derived from a neuropeptide-like protein also present in normal islets. Proc Natl Acad Sci USA 84:3881-3885

5. Cooper GJS, Willis AC, Clark A, Turner RC, Sim RB, Reid KBM (1987) Purification and characterization of a peptide from amyloid-rich pancreases of type 2 diabetic patients. Proc Natl Acad Sci USA 84:8628-8632

6. Kahn SE, D'Alessio DA, Schwartz MW et al (1990) Evidence of cosecretion of islet amyloid polypeptide and insulin by $\beta$-cells. Diabetes 39:634-638

7. Westermark P, Engstrom U, Johnson KH, Westermark GT, Betsholtz C (1990) Islet amyloid polypeptide: pinpointing amino acid residues linked to amyloid fibril formation. Proc Natl Acad Sci USA 87:5036-5040

8. Lorenzo A, Razzaboni B, Weir GC, Yankner BA (1994) Pancreatic islet cell toxicity of amylin associated with type-2 diabetes mellitus. Nature 368:756-760

9. Mirzabekov TA, Lin MC, Kagan BL (1996) Pore formation by the cytotoxic islet amyloid peptide amylin. J Biol Chem 271:1988-1992

10. Janciauskiene S, Ahren B (1998) Different sensitivity to the cytotoxic action of IAPP fibrils in two insulin-producing cell lines, HIT-T15 and RINm5F cells. Biochem Biophys Res Commun 251:888-893

11. Janson J, Ashley RH, Harrison D, McIntyre S, Butler PC (1999) The mechanism of islet amyloid polypeptide toxicity is membrane disruption by intermediate-sized toxic amyloid particles. Diabetes 48:491-498

12. Zhang S, Liu J, Saafi EL, Cooper GJ (1999) Induction of apoptosis by human amylin in RINm5F islet beta cells is associated with enhanced expression of p53 and p21WAF1/ CIP1. FEBS Lett 455:315-320

13. Harroun TA, Bradshaw JP, Ashley RH (2001) Inhibitors can arrest the membrane activity of human islet amyloid polypeptide independently of amyloid formation. FEBS Lett 507:200-204 
14. Sakuraba H, Mizukami H, Yagihashi N, Wada R, Hanyu C, Yagihashi S (2002) Reduced beta cell mass and expression of oxidative stress-related DNA damage in the islet of Japanese type II diabetic patients. Diabetologia 45:85-96

15. Zraika S, Hull RL, Udayasankar J et al (2009) Oxidative stress is induced by islet amyloid formation and time-dependently mediates amyloid-induced beta cell apoptosis. Diabetologia 52:626-635

16. Laybutt DR, Preston AM, Akerfeldt MC et al (2007) Endoplasmic reticulum stress contributes to beta cell apoptosis in type 2 diabetes. Diabetologia 50:752-763

17. Hull RL, Zraika S, Udayasankar J, Aston-Mourney K, Subramanian SL, Kahn SE (2009) Amyloid formation in human IAPP transgenic mouse islets and pancreas, and human pancreas, is not associated with endoplasmic reticulum stress. Diabetologia 52:1102-1111

18. Huang CJ, Haataja L, Gurlo T et al (2007) Induction of endoplasmic reticulum stress-induced beta cell apoptosis and accumulation of polyubiquitinated proteins by human islet amyloid polypeptide. Am J Physiol Endocrinol Metab 293:E1656-E1662

19. Huang CJ, Lin CY, Haataja L et al (2007) High expression rates of human islet amyloid polypeptide induce endoplasmic reticulum stress mediated beta cell apoptosis, a characteristic of humans with type 2 but not type 1 diabetes. Diabetes 56:2016-2027

20. Maedler K, Schulthess FT, Bielman C et al (2008) Glucose and leptin induce apoptosis in human beta cells and impair glucosestimulated insulin secretion through activation of c-Jun N-terminal kinases. FASEB J 22:1905-1913

21. Cunha DA, Hekerman P, Ladriere L et al (2008) Initiation and execution of lipotoxic ER stress in pancreatic beta cells. J Cell Sci 121:2308-2318

22. Ammendrup A, Maillard A, Nielsen K et al (2000) The c-Jun amino-terminal kinase pathway is preferentially activated by interleukin-1 and controls apoptosis in differentiating pancreatic beta cells. Diabetes 49:1468-1476

23. Major CD, Wolf BA (2001) Interleukin-1beta stimulation of c-Jun $\mathrm{NH}(2)$-terminal kinase activity in insulin-secreting cells: evidence for cytoplasmic restriction. Diabetes 50:2721-2728

24. Kaneto H, Matsuoka TA, Nakatani Y et al (2005) Oxidative stress, ER stress, and the JNK pathway in type 2 diabetes. J Mol Med (Berl) 83:429-439

25. Zhang S, Liu J, MacGibbon G, Dragunow M, Cooper GJ (2002) Increased expression and activation of c-Jun contributes to human amylin-induced apoptosis in pancreatic islet beta cells. J Mol Biol 324:271-285

26. Zhang S, Liu J, Dragunow M, Cooper GJ (2003) Fibrillogenic amylin evokes islet $\beta$-cell apoptosis through linked activation of a caspase cascade and JNK1. J Biol Chem 278:52810-52819

27. Li XL, Xu G, Chen T et al (2009) Phycocyanin protects INS-1E pancreatic beta cells against human islet amyloid polypeptideinduced apoptosis through attenuating oxidative stress and modulating JNK and p38 mitogen-activated protein kinase pathways. Int J Biochem Cell Biol 41:1526-1535

28. Zhang S, Liu H, Yu H, Cooper GJ (2008) Fas-associated death receptor signaling evoked by human amylin in islet beta cells. Diabetes 57:348-356

29. Thomas HE, Biden TJ (2009) Bad news for beta cell apoptosis. Diabetes 58:1725-1727
30. Abdelli S, Puyal J, Bielmann C et al (2009) JNK3 is abundant in insulin-secreting cells and protects against cytokine-induced apoptosis. Diabetologia 52:1871-1880

31. D'Alessio DA, Verchere CB, Kahn SE et al (1994) Pancreatic expression and secretion of human islet amyloid polypeptide in a transgenic mouse. Diabetes 43:1457-1461

32. Andrikopoulos S, Verchere CB, Terauchi K, Kadowaki T, Kahn SE (2000) B-cell glucokinase deficiency and hyperglycemia are associated with reduced islet amyloid deposition in a mouse model of type 2 diabetes. Diabetes 49:2056-2062

33. Zraika S, Hull RL, Udayasankar J et al (2007) Glucose- and timedependence of islet amyloid formation in vitro. Biochem Biophys Res Commun 354:234-239

34. Bonny C, Oberson A, Negri S, Sauser C, Schorderet DF (2001) Cell-permeable peptide inhibitors of JNK: novel blockers of beta cell death. Diabetes 50:77-82

35. Maedler K, Sergeev P, Ris F et al (2002) Glucose-induced B cell production of IL-1ß contributes to glucotoxicity in human pancreatic islets. J Clin Invest 110:851-860

36. Masters SL, Dunne A, Subramanian SL et al (2010) Activation of the NLRP3 inflammasome by islet amyloid polypeptide provides a mechanism for enhanced IL-1beta in type 2 diabetes. Nat Immunol 11:897-904

37. Abdelli S, Ansite J, Roduit R et al (2004) Intracellular stress signaling pathways activated during human islet preparation and following acute cytokine exposure. Diabetes 53:2815-2823

38. Law E, Lu S, Kieffer TJ et al (2010) Differences between amyloid toxicity in alpha and beta cells in human and mouse islets and the role of caspase-3. Diabetologia 53:1415-1427

39. Benn SC, Woolf CJ (2004) Adult neuron survival strategiesslamming on the brakes. Nat Rev Neurosci 5:686-700

40. McKenzie MD, Jamieson E, Jansen ES et al (2010) Glucose induces pancreatic islet cell apoptosis that requires the $\mathrm{BH} 3$-only proteins Bim and Puma and multi-BH domain protein Bax. Diabetes 59:644-652

41. Thomas HE, McKenzie MD, Angstetra E, Campbell PD, Kay TW (2009) Beta cell apoptosis in diabetes. Apoptosis 14:1389-1404

42. Mehmeti I, Lenzen S, Lortz S (2010) Modulation of Bcl-2-related protein expression in pancreatic beta cells by pro-inflammatory cytokines and its dependence on the antioxidative defense status. Mol Cell Endocrinol 332:88-96

43. Li XL, Chen T, Wong YS et al (2011) Involvement of mitochondrial dysfunction in human islet amyloid polypeptideinduced apoptosis in INS-1E pancreatic beta cells: an effect attenuated by phycocyanin. Int J Biochem Cell Biol 43:525-534

44. Sarkar SA, Kutlu B, Velmurugan K et al (2009) Cytokinemediated induction of anti-apoptotic genes that are linked to nuclear factor kappa-B (NF-kappaB) signalling in human islets and in a mouse beta cell line. Diabetologia 52:1092-1101

45. Rodriguez-Mulero S, Montanya E (2008) Islet graft response to transplantation injury includes upregulation of protective as well as apoptotic genes. Cell Transplant 17:1025-1034

46. Liu J, Lin A (2005) Role of JNK activation in apoptosis: a doubleedged sword. Cell Res 15:36-42

47. Alavez S, Vantipalli MC, Zucker DJ, Klang IM, Lithgow GJ (2011) Amyloid-binding compounds maintain protein homeostasis during ageing and extend lifespan. Nature 472:226-229 